\title{
Pseudomonas putrefaciens as a cause of infection in humans
}

\author{
J. DEBOIS, ${ }^{1}$ H. DEGREEF, ${ }^{1}$ J. VANDEPITTE, ${ }^{2}$ AND J. SPAEPEN ${ }^{2}$
}

From the Departments of Dermatology $y^{1}$ and Bacteriology ${ }^{2}$, St Raphaël University Hospital, B-3000 Leuven, Belgium

SYNOPSIS Pseudomonas putrefaciens, a strongly $\mathrm{H}_{2} \mathrm{~S}$-producing pseudomonad, was isolated from 10 human infections over a two-year period. In one patient the organism was repeatedly isolated from a phlegmone developing in the depth of a varicose leg ulcer. This is the first report on the occurrence of Ps. putrefaciens in humans outside the USA and the first to provide the detailed account of a clinical observation where the opportunistic pathogenic role of this unfamiliar organism has been sufficiently documented.

Data are presented on the bacteriological properties and on the antibiotic sensitivity of $P s$. putrefaciens.

Although Pseudomonas aeruginosa is by far the most common pathogenic species of the genus Pseudomonas, several other species have recently attracted the attention of the clinical bacteriologist.

Recognition of these species has long been hampered by the lack of a clear classification system for nonfermentative Gram-negative bacteria and by the considerable confusion in their nomenclature. Improvements in bacteriological methods and the increased incidence of opportunistic and nosocomial infections have stimulated interest in Pseudomonas species other than Ps. aeruginosa. Simple criteria for characterization of unusual Pseudomonas species have been presented in a series of well-documented papers (Gilardi, 1971, 1972; Von Graevenitz, 1973).

Although easy to recognize because of its abundant hydrogen sulphide production, Ps. putrefaciens is one of the least well-known pseudomonads in medical bacteriology, and we have seen no mention of the isolation of this species in the European literature.

The first human isolates of a nonfermenting, $\mathrm{H}_{2}$ S-producing Gram-negative rod with polar flagellation were described by King in 1964, who gave them the provisional label 'lb'. In 1970, von Graevenitz and Simon reported 13 isolations of the same microorganism from different clinical speci-

Requests for reprints should be addressed to Professor $\mathbf{J}$. Vandepitte, Department of Microbiology, St-Raphaël University Hospital, B-3000 Leuven, Belgium.

Received for publication 7 July 1975. mens. It was recognized by Hugh (1970) that the ' $l b$ ' bacterium, isolated by the previous observers, was identical with Ps. putrefaciens. This bacterium, first isolated from butter, was originally described under the epithet of Achromobacter putrefaciens (Derby and Hammer, 1931) and later transferred to the genus Pseudomonas (Long and Hammer, 1941). Similar bacteria were described by other investigators under different names-Pseudomonas rubescens (Pivnick, 1955) and Flavobacterium group 4 (Pedersen et al, 1970). These epithets are now believed to be synonymous with Ps. putrefaciens. More recently, a subdivision of the species into two biotypes on the basis of some growth and metabolic properties has been proposed (Levin, 1972) and independently supported (Riley et al, 1972).

This report presents data on the isolation and the clinical significance of this unusual pseudomonad in a large clinical laboratory. The history of the single patient, in whom the pathogenicity of this bacterium could be unequivocally demonstrated, is given in greater detail.

\section{Material and Methods}

The strains were recovered from clinical specimens submitted to the laboratory for routine bacteriological examination. All strains were isolated on MacConkey agar and attracted attention by the combination of blackening on Kligler iron agar and a positive oxidase reaction. Final identification was based on routine biochemical tests (Edwards and 
Ewing, 1972). Sensitivity testing was done using the Bauer-Kirby single disk method (Bauer et al, 1966).

\section{Results}

From February 1972 to December 1974, four strains (excluding repeated isolations from the same patient) of Ps. putrefaciens were obtained from clinical specimens submitted to our laboratory. An additional six cultures were received for identification or further investigation from four other Belgian hospitals. Clinical data on these isolates are summarized in table I.

In cases 1 and 3 , repeated isolations from the sputum over a relatively long interval proved that the bacterium was not an accidental laboratory contaminant nor a transient saprophyte, but that the respiratory tract of both patients was actually colonized with this microorganism. However, its aetiological role in the causation of infection could not be established. In cases 5 and 7 subsequent urine cultures were negative for Ps. putrefaciens. Only in patient 9 was there convincing evidence that $P$ s. putrefaciens had invaded the tissues and that it acted as an opportunistic human pathogen. The history of this patient is therefore presented in full below.

\section{Case history (patient 9)}

On 19 September 1974 an 82-year-old woman was admitted as an emergency case to our hospital after an undefined form of syncope or transient attack. The patient was in a poor general condition and physical examination showed bilateral oedema of the legs. Laterally on the right leg confluent ulcera- tions were seen surrounded by a warm erythematous infiltrated zone. The ulcerations covered an area of approximately $10 \mathrm{~cm}$ diameter. On the supramalleolar side of the left leg there were also many smal ulcerations forming a confluent plaque of about $4 \mathrm{~cm}$ diameter. These ulcers were covered with a fibrinoid necrotic purulent exudate, in part showing a tendency towards granulation. The aspect of the surrounding skin was definitely erysipeloid, with wrinkled and scaly skin as typically seen in elephantiasis. The dermatological condition of the patient was classified as an 'erysipelas-like complication of varicose ulcers of the leg'.

Interrogation was difficult but revealed that the patient had suffered for more than 16 months from open wounds on both legs for which she had repeatedly refused hospitalization. She lived alone, in a state of severe domestic squalor, in extreme selfneglect, surrounded by cats, pigeons, and rabbits, and was cared for from time to time by a visiting home help. Her physician prescribed intermittent courses of oral penicillin and chloramphenicol for treatment of the infected leg ulcers.

On admission a swab of the exudate taken from the deep ulcer on the right leg was brought to the laboratory. Culture of this material gave a 'profuse growth of Pseudomonas sp. and coagulase-negative staphylococci'. Urine culture revealed a significan count (more than $10^{5}$ organisms per $\mathrm{ml}$ ) of Escherichia coli and Proteus vulgaris in the absence of pyuria. Other relevant laboratory findings are summarized in table II.

Treatment consisted of oral nitrofurantoin tablets (Furadantin MC, $4 \times 100 \mathrm{mg}$ per day) for the urinary infection, later replaced by co-trimoxazole (Eusaprim 2 tablets twice a day), which showed good

\begin{tabular}{|c|c|c|c|c|c|c|}
\hline Case & Date & Age & Sex & Primary Diagnosis & Culture Source & Originating Laboratory \\
\hline 1 & Feb 1972 & 48 & $\mathbf{F}$ & Liver cirrhosis and lung tuberculosis & Sputum ${ }^{1}$ & Leuven \\
\hline 2 & Mar 1972 & 20 & $\mathbf{F}$ & Amygdalitis & Tonsillar pus & Bruges (Dr. E. Callewaert) \\
\hline 3 & Jan 1973 & 69 & $\mathbf{M}$ & Tuberculosis and chronic bronchitis & Sputum ${ }^{2}$ & Bonheiden (Dr. R. Van Noyen) \\
\hline 4 & Feb 1973 & 2 & $\mathbf{M}$ & $\begin{array}{l}\text { Urinary infection after indwelling } \\
\text { catheter postop. for phimosis }\end{array}$ & Urine $\left(>10^{5}\right.$ bacteria $\left./ \mathrm{ml}\right)$ & Bruges (Dr. H. Van Landuyt) \\
\hline 5 & Apr 1974 & 51 & $\mathbf{F}$ & $\begin{array}{l}\text { Chronic pyelonephritis (phenacetin } \\
\text { abuse?) }\end{array}$ & Urine $(20000 \mathrm{~b} / \mathrm{ml})$ & Bruges (Dr. E. Callewaert) \\
\hline 6 & May 1974 & $?$ & $\mathbf{F}$ & & Sputum & Aalst (J. Hoegaerts) \\
\hline 7 & July 1974 & 30 & $\mathbf{F}$ & $\begin{array}{l}\text { Pregnancy; } \\
\text { asymptomatic bacteriuria }\end{array}$ & $\begin{array}{l}\text { Urine }\left(>10^{5} \mathrm{~b} / \mathrm{ml}\right) \text { associated with } \\
E \text {. coli and Acinetobacter }\end{array}$ & Leuven \\
\hline 8 & Aug 1974 & 25 & $\mathbf{F}$ & Cystitis & $\begin{array}{l}\text { Urine }\left(>10^{s} \text { bacteria/ml) }\right. \\
\text { associated with Enterobacter }\end{array}$ & Bruges (Dr. E. Callewaert) \\
\hline 9 & Sept 1974 & 82 & $\mathbf{F}$ & $\begin{array}{l}\text { Lymphoedema and varicose } \\
\text { phlegmone of leg }\end{array}$ & Wound exudate 3 & Leuven \\
\hline 10 & Dec 1974 & 40 & $\mathbf{F}$ & Acute bronchitis & Sputum & Leuven \\
\hline
\end{tabular}

Table I Clinical data on human Ps. putrefaciens infections

This strain was again isolated seven weeks later

2Three successive isolations with one week and two week intervals

sSix isolations over a period of one month 


\begin{tabular}{|c|c|c|c|c|}
\hline & Sept 19 & Sept 25 & Oct 15 & Oct 24 \\
\hline $\begin{array}{l}\text { Erythrocyte sedimentation rate } \\
\left(\mathrm{mm} \mathrm{l}^{-1} \mathrm{~h}^{-1}\right)\end{array}$ & & \multicolumn{2}{|l|}{70} & 15 \\
\hline White cell count $/ \mathrm{mm}^{3}$ & \multirow{4}{*}{$\begin{array}{c}16,200 \\
131 \cdot 5 \\
3 \cdot 2\end{array}$} & & & 5,500 \\
\hline Serum sodium (mEq/l) & & & & 140.5 \\
\hline Serum potassium (mEq/l) & & & & 4.5 \\
\hline $\begin{array}{l}\text { Total plasma proteins }(\mathrm{g} / \mathrm{dl}) \\
\text { Albumin }\end{array}$ & & $\begin{array}{l}7 \\
39 \cdot 7 \%\end{array}$ & $\begin{array}{c}6 \cdot 7 \\
51 \cdot 2 \%\end{array}$ & \\
\hline Globulins & & & & \\
\hline$\alpha_{1}$ & & $6.0 \%$ & $2 \cdot 3 \%$ & \\
\hline$\alpha_{2}$ & & $15.9 \%$ & $10.5 \%$ & \\
\hline$\beta$ & & $16.8 \%$ & $16.9 \%$ & \\
\hline$\gamma$ & & $21.6 \%$ & $19 \cdot 2 \%$ & \\
\hline SGOT (IU/I) & & $42 \cdot 5^{\circ}$ & & $7 \cdot 5$ \\
\hline SGPT (IU/I) & & $51 \cdot 5$ & & 8 \\
\hline Serum bilirubin $(\mathrm{mg} / \mathrm{dl})$ & & $2 \cdot 7$ & & 0.6 \\
\hline C. Reactive protein $(\mathrm{mm})$ & & $4 \cdot 5$ & $\mathbf{0}$ & 0 \\
\hline
\end{tabular}

Table II Selected laboratory data of case 9

in vitro activity against the different microorganisms grown from the urine and the exudate. The ulcers were dressed with chloramine cream. The patient was further given a high-protein diet supplemented with a mixture of vitamins and minerals.

On 27 September the deepest ulcer on the right leg was incised and abundant pus oozing from an underlying phlegmone was obtained. Culture showed a profuse and pure growth of a pseudomonad which was now fully identified as Ps. putrefaciens, susceptible to co-trimoxazole. Two days later, control swabs were again cultured with exactly identical results.

Under the combined local and general treatment, the ulceration on the left leg healed completely within three weeks. On the right leg, however, a rather superficial ulceration with a regenerating base persisted. Swabs taken from this site on 9, 10, and 11 October gave no growth.

Antibiotic treatment was stopped on 18 October. A week later a new swab was taken from the small residual ulcer left on the right leg. Culture was again positive for Ps. putrefaciens. Although no further general antibiotic treatment was given, cultures on 30 October and 11 November were again sterile.

Under the effect of further local treatment the lesion progressively healed and the patient was discharged on 22 November with slight oedema of the legs and a marked improvement of her general condition and biochemical serum values (table II).

\section{Bacteriology}

The growth characteristics and the biochemical reactions of the 10 strains isolated from our patients showed a high degree of similarity. All were composed of Gram-negative rods of variable length, growing abundantly on plain bacteriological culture media. Colonies on blood agar were convex, circular, smooth, and opaque with a tan-yellow to brown pigment. A green discolouration of the medium was seen in the zone of heavy growth. On MacConkey agar the organism grew as mucoid, tan, lactose nonfermenting colonies. All strains grew readily on tubes of Kligler iron agar without production of acid. The most salient feature of Ps. putrefaciens, grown on this medium, was the heavy blackening of the stabbed butt due to production of $\mathrm{H}_{2} \mathrm{~S}$. This character, generally evident after overnight incubation, masked the red colour of the butt and explains why this growth pattern was generally first mistaken for Proteus, Salmonella or Citrobacter.

With one exception, all strains were actively motile by means of one polar flagellum. Other biochemical reactions of our cultures are given in table III.

On the basis of their salt tolerance, assessed by growth in Trypticase soy broth containing $6 \% \mathrm{NaCl}$, and their growth on Salmonella-Shigella agar, our 10 isolates could be equally distributed between the two groups postulated by Levin (1972).

Only five strains, including the isolate from our case 9 , were submitted to a full susceptibility test. The results are shown in table IV.

\begin{tabular}{lclr}
\hline Oxidase & + & Phenyl-alanine deaminase & 0 \\
Catalase & $+(0)$ & Malonate & 0 \\
Growth on citrate & 0 & Lysine decarboxylase & 0 \\
Nitrate reduction & + & Arginine dihydrolase & 0 \\
Indole production & $\mathbf{0}$ & Ornithine decarboxylase & + \\
Gelatinase & + & Beta-galactosidase & 0 \\
Urea hydrolysis & $\mathbf{0}($ weak) & OF medium: oxidation of \\
Aesculin hydrolysis & $\mathbf{0}$ & glucose, maltose, lactose, \\
DNase & $+(0)$ & xylose & Variable \\
& & Mannitol & 0 \\
\hline
\end{tabular}

Table III Biochemical reactions of Ps. putrefaciens

( ) exceptional reaction

\begin{tabular}{lll}
\hline Sensitive & Variable & Resistant \\
\hline $\begin{array}{l}\text { erythromycin } \\
\text { tetracyclines } \\
\text { chloramphenicol }\end{array}$ & $\begin{array}{l}\text { ampicillin } \\
\text { cephalosporins } \\
\text { colistin }\end{array}$ & $\begin{array}{l}\text { penicillin G } \\
\text { methicillin } \\
\text { sulphonicillin }\end{array}$ \\
$\begin{array}{l}\text { nitrofurane } \\
\text { co-trimuxazole }\end{array}$ & streptomycin \\
kanamycin & & \\
gentamicin & & \\
\hline
\end{tabular}

Table IV Antibiotic susceptibility of five strains of Ps. putrefaciens

\section{Discussion}

Ps. putrefaciens is a saprophyte with a wide distribution in nature. It has been isolated from butter, milk, fish, eggs, stream and lake water, sewage, natural gas, and petroleum brines and has been reported as a spoilage organism in butter and fish (Long and Hammer, 1941; Hugh, 1970). 
Among the 22 isolates, collected at the Center for Disease Control, Atlanta, Georgia and listed by King (1964), several came from human sourcesstored blood, spinal fluid, urine, faeces, wounds, sputum, and ear discharge. Among the 13 strains, described by von Graevenitz and Simon (1970), five were from patients with chronic otitis, four originated from chronic leg ulcers, three from sputum, and one from urine. Two of the strains described by Pedersen and associates (1970) were recovered from the faeces of premature infants and one from a foot wound. Although 12 clinical isolates were mentioned by Gilardi, only two strains were documented: one was associated with otitis media and a second was recovered from the wound of an infected open fracture of the tibia.

From all the published isolations, only one strain, repeatedly isolated from a chronic otitis media, was said to be aetiologically linked to the disease state in which it was cultivated (von Graevenitz and Simon, 1970).

In all the literature reports and in the majority of our own observations, the clinical information is so poor that no general conclusion can be drawn on the clinical significance of Ps. putrefaciens. In most cases it can be judged that the organism was a contaminant or, at most a saprophyte, thriving as a secondary invader on previously damaged tissues.

The present report contains the first known documented case of an infectious process where the aetiologic significance of Ps. putrefaciens could be clearly demonstrated by its presence, over a long period of time, in a deep phlegmone, underlying a varicose ulcer of the leg.

Although widely distributed in nature, $P S$. aeruginosa is best known as a highly resistant, hospital-acquired, opportunistic pathogen responsible for life-threatening infections in predisposed patients after major surgery, extensive burns, and steroid and antibiotic treatment. The disease spectrum associated with $P$ s. putrefaciens is clearly different. Recorded infections were generally benign and commonly limited to the superficial mucosae, the damaged skin, and the bladder urine. Most of our cases seem to have acquired their infection in the community, a point that had already been stressed by von Graevenitz and Simon (1970). Antibiotic resistance was not considered a problem and most of our strains, as were those of other observers (Pedersen et al, 1970; von Graevenitz, 1973), were highly susceptible to common antibiotics, even to erythromycin, which in general is not active against Gram-negative bacilli.

Varicose leg ulcers are frequently infected with $P$ s. aeruginosa even outside the hospital (Verburgvan der Zwan and Siem, 1973). There is evidence from our observation and from the experience of others (von Graevenitz and Simon, 1970) that Ps. $\vec{\partial}$ putrefaciens shares the same affinity for necrotic tissue with poor circulation. The psychrophilic nature (von Graevenitz, 1973) of the latter organism makes it particularly well adapted to multiply in the colder, devitalized tissues of a varicose ulcer $\bar{\omega}$ on the lower extremities. In our patient, the lack of $\mathbb{\mathbb { D }}$ personal hygiene and the intimate contact with pet animals may in turn have contributed to the contamination of the leg ulcer with soil saprophytes.

The authors are deeply indebted to Dr. R. E. $\stackrel{\omega}{\circ}$ Weaver (CDC, Atlanta), who kindly confirmed the identity of three isolates. They are also grateful to their Belgian colleagues who were responsible for 9 the isolation of six of the strains reviewed in this $\vec{N}$ article.

\section{References}

Bauer, A. W., Kirby, W. M. M., Sherris, J. C., and Turck,

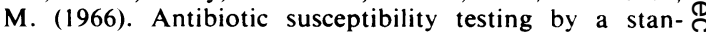
dardized single disk method. Amer. J. clin. Path., 45, 493-496.

Derby, H. A., and Hammer, B. W. (1931). Bacteriology of butter. IV. Bacteriological studies in surface taint butter. Bull. La agric. Exp. Stn., 145, 387-416.

Edwards, P. R. and Ewing, W. H. (1972). Identification of Enterobacteriaceae, 3rd ed. Burgess, Minneapolis.

Gilardi, G. L. (1971). Characterization of Pseudomori species isolated from clinical specimens. Appl. Microbio 21, 414-419.

Gilardi, G. L. (1972). Infrequently encountered Pseudomonas species causing infection in humans. Ann. intern. 요 Med., 77, 211-215.

Hugh, R. (1970). A practical approach to the identification $\overrightarrow{\vec{B}}$ of certain nonfermentative gram-negative rods encountered in clinical specimens. Publ. Hlth Lab., 28, 168-187.

King, E. O. (1964). The identification of unusual pathogenic gram-negative bacteria. National Communicable Disease? Center, Atlanta.

Levin, R. E. (1972). Correlation of DNA base composition and metabolism of Pseudomonas putrefaciens isolates from $\overline{-}$ food, human clinical specimens, and other sources. Antonie 3 . v. Leeuwenhoek, 38, 121-127.

Long, H. F. and Hammer, B. W. (1941). Distribution of Pseudomonas putrefaciens. J. Bact., (Abstract), 41, 100-101.

Pedersen, M. M., Marso, E., and Pickett, M. J. (1970). 을 Nonfermentative bacilli associated with man. III. Pathogenicity and antibiotic susceptibility. Amer. J. clin. Path., 54, 178-192.

Pivnick, H. (1955). Pscudomonas rubescens, a new species $N$ from soluble oil emulsions. J. Bact., 70, 1-6.

Riley, P. S., Tatum, H. W., and Weaver, R. E. (1972). N Pscudomonas putrefaciens isolates from clinical specimens. N Appl. Microbiol., 24, 798-800.

Verburg-van der Zwan, N., and Siem, T. H. (1973). Besmetting van ulcera cruris met Pseudomonas aeruginosa in eeno dermatologische kliniek. Ned. T. Geneesk, 117, 631-637.

Von Graevenitz, A. (1973). Clinical microbiology of unusual Pseudomonas species. Progr. clin. Path., 5, 185-218.

Von Graevenitz, A. and Simon, G. (1970). Potentially pathogenic, nonfermentative, $\mathrm{H}_{2} \mathrm{~S}$-producing Gram-negative움 rod (1b). Appl. Microbiol., 19, 176. 